\title{
Thermal behavior and indirect life test of large-area OLED lighting panels
}

\author{
Huiqing Pang, Lech Michalski ${ }^{*}$ Michael S Weaver, Ruiqing Ma and Julie J Brown
}

\author{
* Correspondence: \\ lamichalski@udcoled.com \\ Universal Display Corporation, 375 \\ Phillips Boulevard, Ewing, NJ 08618, \\ USA
}

\begin{abstract}
In this work, we studied the thermal behavior and addressed the challenges of life testing of large area OLED devices. In particular, we developed an indirect method to accurately calculate the life time of large-area OLED lighting panels without physically life-testing the panels. Using small area OLEDs with structures identical with the tested panels, we performed the life tests at desired driving current densities at different temperatures and extracted the relationship between junction temperature and the lifetime for the particular device. By measuring the panel junction temperature during operation under the same current density and using the life time measured on small area test devices, we determine the lifetime of the panels based on the thermal dependence. We test this methodology by predicting the life time of white PHOLED panels and then physically testing the panels. The typical result for the lifetime to $80 \%$ of the initial luminance (LT80) of the panel at a constant dc current density of $10 \mathrm{~mA} / \mathrm{cm}^{2}$ $\left(3800 \mathrm{~cd} / \mathrm{m}^{2}\right)$, was predicted to be 526 hours in good agreement with the actual life-test at $10 \mathrm{~mA} / \mathrm{cm}^{2}$ of $512 \mathrm{hrs}$. This good agreement, confirmed in different experiments, validates this novel technique as a practical life time predictor of large-area OLED lighting panels in a time saving manner.
\end{abstract}

Keywords: OLED lighting panel; Thermal; Life test; Large-area; PHOLED; Junction temperature; Lifetime

\section{Background}

Organic Lighting Emitting Devices (OLEDs) are considered promising candidates as next-generation solid state light sources due to their unique and exceptional features: thin form, lightweight, energy-efficient, low operational temperature, and large-area diffuse light sources with excellent visual quality [1-3]. Particularly, white OLED panels as future general illumination devices have developed rapidly over the past decades, and high-performance, long-lifetime and thin flexible white OLEDs have been demonstrated [4-9]. Today, commercial OLED lighting panels and luminaries are available in the market place with comparable performance to some LED lamps [10-17]. Impressive progress has been reached in the design of small-area devices with excellent power efficacy, good CIE and CRI numbers and long life times. A number of design challenges remain, however, to achieve similar parameters in large area panels at volume manufacturing scales. One technology challenge is the design of low resistance electrical connections while maintaining maximum aperture area. Additionally, achieving long lifetime at high luminance at the panel level is a challenge. Typically, the life time

\section{Springer}

(c) 2014 Pang et al.; licensee Springer. This is an Open Access article distributed under the terms of the Creative Commons Attribution License (http://creativecommons.org/licenses/by/4.0), which permits unrestricted use, distribution, and reproduction in any medium, provided the original work is properly credited. 
of the panels is reduced relative to small active area devices with the same structures. Poorer heat dissipation combined with larger Joule heating by the ITO substrates in the large-area devices are generally accepted explanations. The design work is typically focused on the above problems. Life testing of the panels is a necessary component of the design projects. Standard accelerated life testing of the large panels can be costly and time-consuming. The simplified panel test reported here is one approach to solving this problem.

\section{Thermal behavior of OLED panels}

One of the attractive features of OLEDs is the low operational temperature, which makes the panel or 'bulb' cool to touch. This is very different from LEDs, which generate a large amount of heat during operation and thus require additional heat sinking [18-20] in order to create a low temperature product. The fundamental reason for this contrasting thermal behavior is that LEDs are a chip point source and therefore have much higher power density in order to output a target luminous flux. Heat generated due to the high power has very little surface area to dissipate. In contrast, as an area light source, OLED panels operate at a lower power density for the same light output, and at the same time have a larger surface area for thermal dissipation. This situation is further improved with the incorporation of highly-efficient phosphorescent emitters which enable up to $100 \%$ internal quantum efficiency [21,22]. Phosphorescent OLEDs (PHOLEDs) consume much less power than fluorescent OLEDs at the same light output and hence operate at even lower temperature [4]. The white PHOLED architecture used in this study contains only six organic layers including two emissive layers for red-green and light blue emission [4]. Figure 1a shows a photo image of a $19.11 \mathrm{~cm}^{2}$ white PHOLED panel and Figure $1 \mathrm{~b}$ shows the IR image of the panel driven at $4,000 \mathrm{~cd} / \mathrm{m}^{2}$ (equivalent to a luminous emittance of $10,000 \mathrm{~lm} / \mathrm{m}^{2}$ ) after reaching thermal equilibrium. The ambient temperature was maintained at $18^{\circ} \mathrm{C}$ during the IR imaging. The power efficacy of the panel is $52 \mathrm{~lm} / \mathrm{W}$ at $4,000 \mathrm{~cd} / \mathrm{m}^{2}$. This includes a 1.5 times efficacy enhancement achieved by adding a light extraction block. As can be seen from the IR image in Figure 1b, the maximum operational temperature of the panel is less than $22^{\circ} \mathrm{C}$, which is only $4^{\circ} \mathrm{C}$ above the ambient environment.

\section{Methods}

\section{Life test of small OLED pixels}

Although the operational temperature rise for OLEDs is significantly lower than inorganic LEDs, it does impact the lifetime of an OLED. Specifically, a $10^{\circ} \mathrm{C}$ temperature rise results in a 1.65 times life time reduction for the white OLED device used in this study. Therefore, it is important to minimize the operating temperature of OLED panels in order to enhance device lifetime. The conventional method to determine the lifetime of OLEDs is accelerated lifetime testing (ALT) [23], which is also commonly used in other electronic devices, such as photovoltaic devices [24], and LEDs [25]. In this method, the lifetime at the targeted luminance level is extrapolated from lifetimes measured at higher luminance levels. For a small-area OLED device (less than $1 \mathrm{~cm}^{2}$ and has a non-active to active area ratio much larger than 1) this ALT method is reliable because the heat produced by high current densities can be dissipated. The ability 

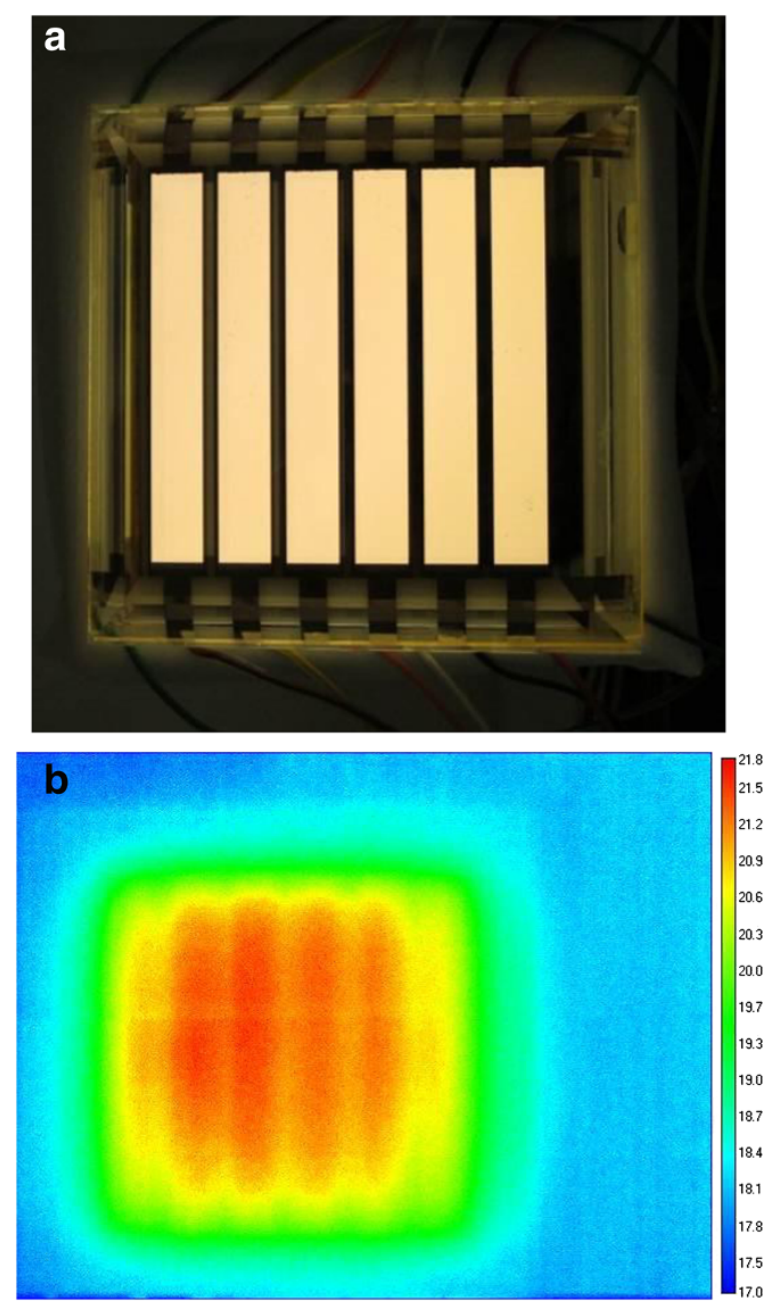

Figure 1 Standard picture (a) and infrared image (b) of a $1911 \mathrm{~mm}^{2}$ white PHOLED panel driven at $4,000 \mathrm{~cd} / \mathrm{m}^{2}$.

to dissipate this heat ensures a device performance without thermally induced variation $[26,27]$. A relatively accurate extrapolation from high to low current density is possible, using the simple relationship

$$
t_{2}=t_{1} \times\left(L_{1} / L_{2}\right)^{A F}
$$

where $A F$ is the acceleration factor; $t_{2}$ is the extrapolated lifetime of the individual OLED device at an initial luminance level $L_{2}$; and $t_{1}$ is the measured lifetime with an initial luminance level $L_{1}$.

Here we show an example of determining the lifetime of a small-area $\left(2 \mathrm{~mm}^{2}\right)$ white OLED device using the conventional ALT method. The test pixels were fabricated and put onto life test at room temperature and at accelerated constant current densities of 10,20 and $40 \mathrm{~mA} / \mathrm{cm}^{2}$. Luminance was then recorded as a function of time and plotted in Figure 2. The time taken to reach $80 \%$ of initial luminance, LT80, at each current density is then extracted from Figure 2, and the relationship between LT80 and 


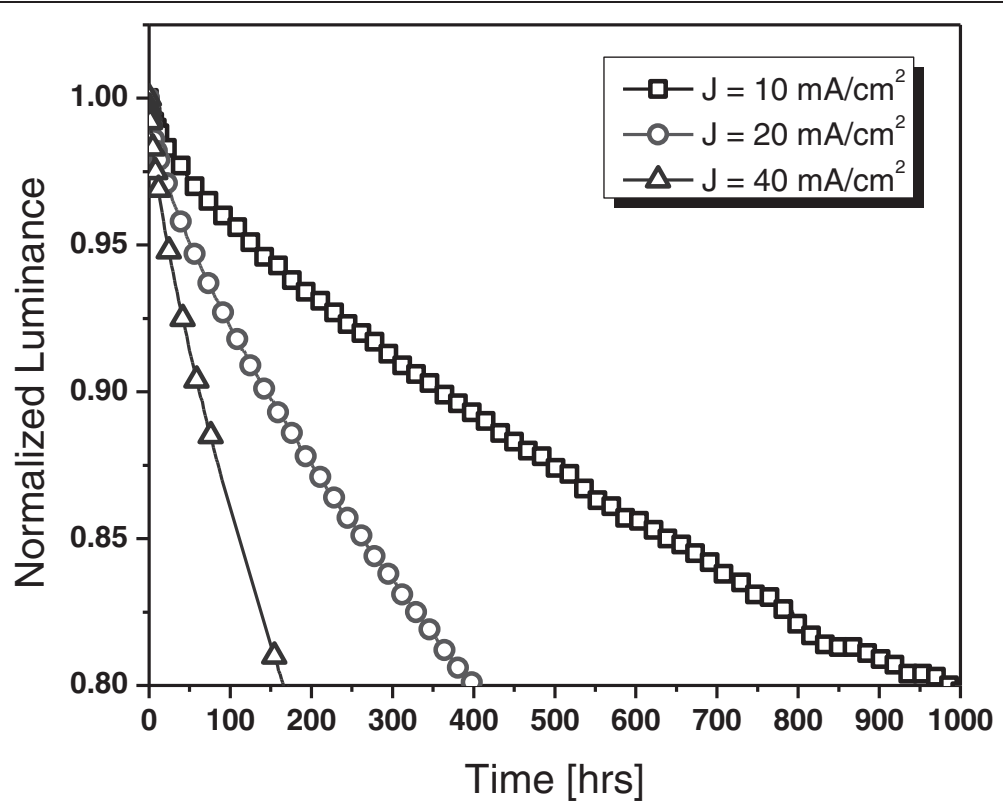

Figure 2 Lifetime curves for small-area white OLED pixels under ALT. Data is shown for life test at 10 (squares), 20 (circles) and 40 (triangles) $\mathrm{mA} / \mathrm{cm}^{2}$.

correspondent luminance (in semi-log scale) is plotted in Figure 3. For this specific device structure, the fitting equation is

$$
L T 80=1.259 \times 10^{8} L^{-1.43}
$$

where $\mathrm{L}$ is the luminance and the acceleration factor is 1.43. The linear dependence of LT80 on luminance (in semi-log scale) can be used to extrapolate the lifetime of the

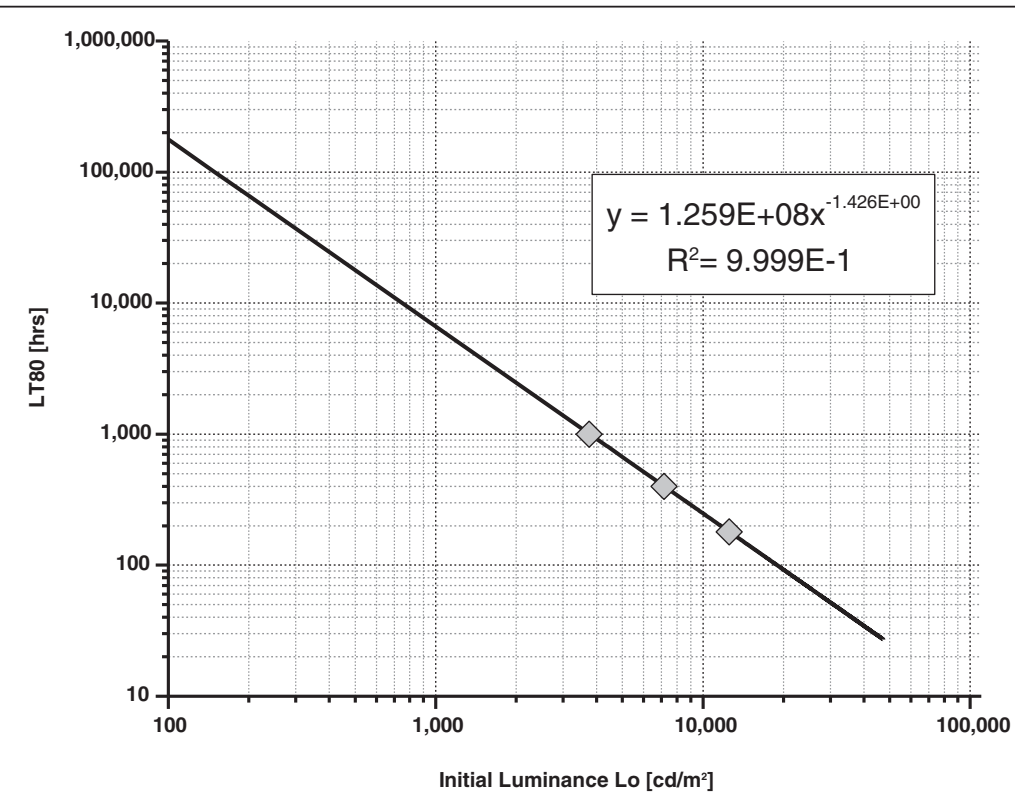

Figure 3 ALT plot for small-area white OLED test pixels at 10, 20 and $40 \mathrm{~mA} / \mathrm{cm}^{2}$. The acceleration factor $\mathrm{AF}=1.43$. 
pixels at various luminance levels from the fitting equation. For instance, LT80 at an initial luminance of $1,000 \mathrm{~cd} / \mathrm{m}^{2}$ is calculated to be $6,638 \mathrm{hrs}$.

The ALT process relies on the assumption that the degradation mechanism is essentially the same at the high current densities used to measure the acceleration factor as it is at the extrapolated lower current densities. However, this process is not suitable to accurately predict lifetimes of devices when different degradation mechanisms are introduced during the accelerated testing of a large-area OLED lighting panel. This is because, at high current density, even the most efficient large-area OLED panels generate heat over a large area that cannot be easily dissipated. This heat is typically generated by Joule heating in the bus lines, electrodes and non-emissive exciton recombination. This can lead to increased temperatures and/or temperature gradients across the OLED panel, which may result in faster and non-uniform aging [28]. Therefore, the ALT method is not accurate in determining the lifetime of large-area OLED panels.

Although in-situ direct life testing can be applied to large-area OLED panels [29,30], it can be very time-consuming and the test may fail due to catastrophic panel failure. Electrical shorting is a typical failure mode, which may cause an undesired abortion of the test. Therefore, it is essential to develop a reliable method to accurately and efficiently measure the lifetime of large-area OLED panels.

\section{New life testing method}

Here we developed a new approach to indirectly test the life time of large-area OLED panels by determining the junction temperature of the panel at the target luminance level and to provide an accurate prediction of the panel lifetime. The junction temperature of electronic devices, such as LEDs, has long been studied and measured for the purpose of understanding and improving device performance [31,32]. For LEDs, "junction" refers to the hotspot between $\mathrm{p}$ - and n- types of semiconductor that form the active diode and the temperature of the "junction" is typically the highest across the entire device, higher than the exterior temperature of the electronic device during operation. In an OLED device, junction temperature may be broadly defined as the temperature within the organic stack, and in particular, within the emissive layer (EML) where the excitons emit light. For OLEDs, device performance, particularly lifetime, is closely related to their junction temperature [4]. The junction temperature of OLEDs can be measured using the K-factor method [33]. By measuring the junction temperature, we are able to predict the lifetime of an OLED panel accurately in a time saving manner. This lifetime data represents the longest lifetime that can be achieved for the given OLED stack and panel layout if the panel is well encapsulated and does not suffer catastrophic failure such as electrical shorting. The new technique involves the following steps (also shown in a schematic block diagram presented in Figure 4):

(a) Fabricate a series of small-area test pixels with an equivalent organic stack to the one used in the large-area OLED lighting panel whose life time is to be determined.

(b)Life-test pixels at target current densities (i.e. luminance levels) at a range of ambient temperatures in a thermally controlled environment.

(c) Plot lifetime (LT) vs. reciprocal ambient temperature in semi-log scale at target current density that provides the target luminance $L_{o}$.

(d)Provide the large-area OLED light panel that needs to be measured. 


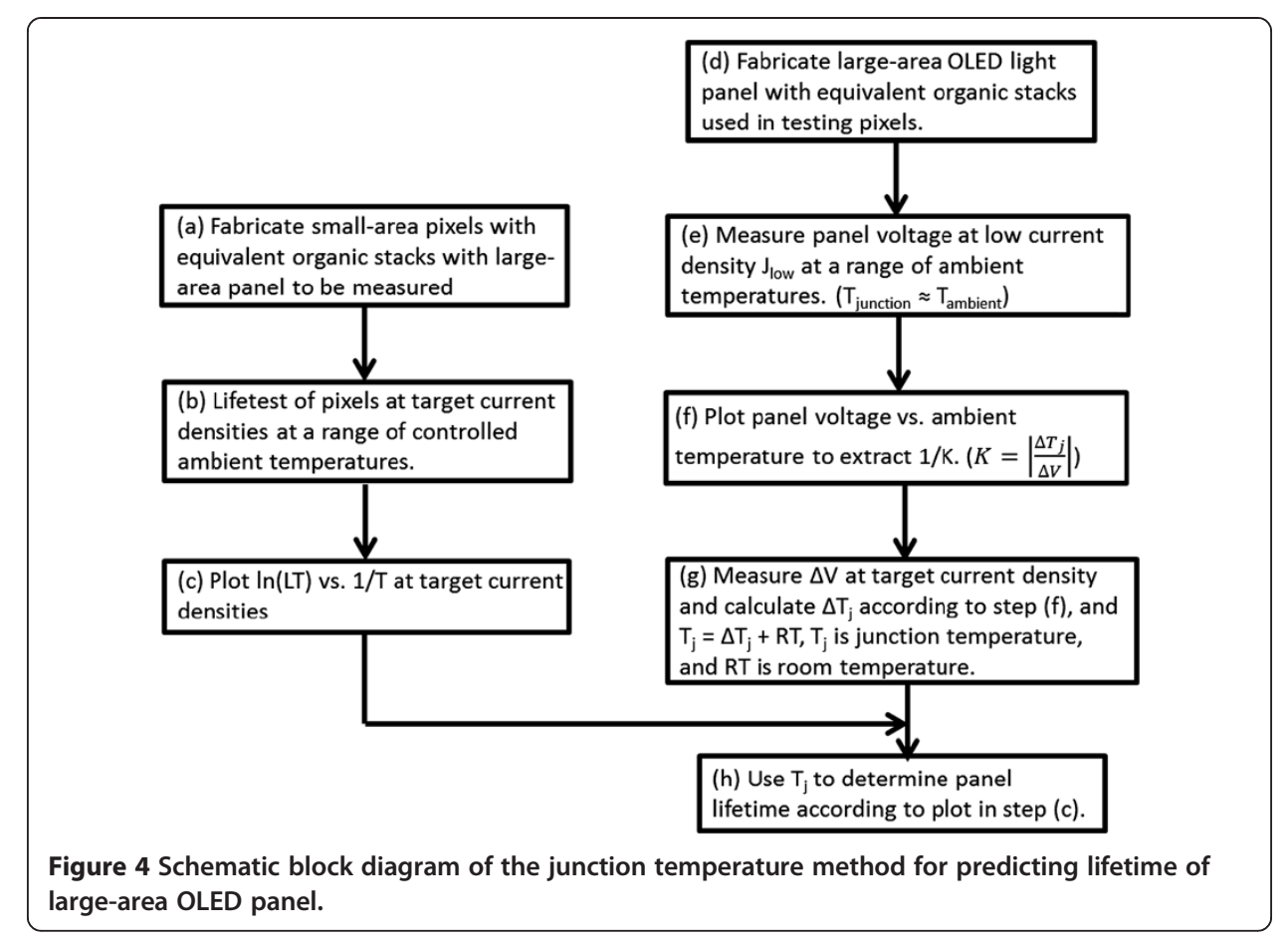

(e) Place the panel into a thermally controlled environment and measure voltage $V$ as a function of ambient temperature $T$ at a non-Joule heating current density $J_{\text {low }}$ (e.g. $0.1 \mathrm{~mA} / \mathrm{cm}^{2}$ ), such that $T \approx T_{j}$.

(f) Plot voltage vs. ambient temperature from step (e). The gradient of this plot gives $1 / K$, where $K$ is the " $K$-factor" for the given OLED device stack and the testing large-area panel layout, shown in Equation 3 below.

$$
K=\left|\frac{\Delta T_{j}}{\Delta V}\right|
$$

(g) Measure $\Delta V$ at target current density $J_{\text {high }}$ and calculate $\Delta T_{j}$ according to Equation 3. Then calculate junction temperature $T_{j}$ using Equation 4 below,

$$
T_{j}=\Delta T_{j}+R T
$$

where $R T$ is the room temperature.

(h) $T_{j}$ is then be used alongside (c) to determine lifetime for the OLED device stack in the given panel architecture.

\section{Results and discussions}

To verify the method, we prepared $2 \mathrm{~mm}^{2}$ white OLED test pixels and a $1911 \mathrm{~mm}^{2}$ white OLED panel, as shown in Figures $5 \mathrm{a}$ and b respectively. The testing pixels and the panel have the same device structure. This is also the same structure used as the example to explain the ALT method in the previous section.

The proposed method started with life-testing of the $2 \mathrm{~mm}^{2}$ test pixels at a target current density of $10 \mathrm{~mA} / \mathrm{cm}^{2}$, at the following temperatures $T: 22^{\circ} \mathrm{C}, 35^{\circ} \mathrm{C}, 45^{\circ} \mathrm{C}, 55^{\circ} \mathrm{C}$ and $70^{\circ} \mathrm{C}$. The ambient temperatures were well controlled so that the device junction temperature $T_{j} \approx T$. The time taken to reach LT80 was recorded at each temperature. 

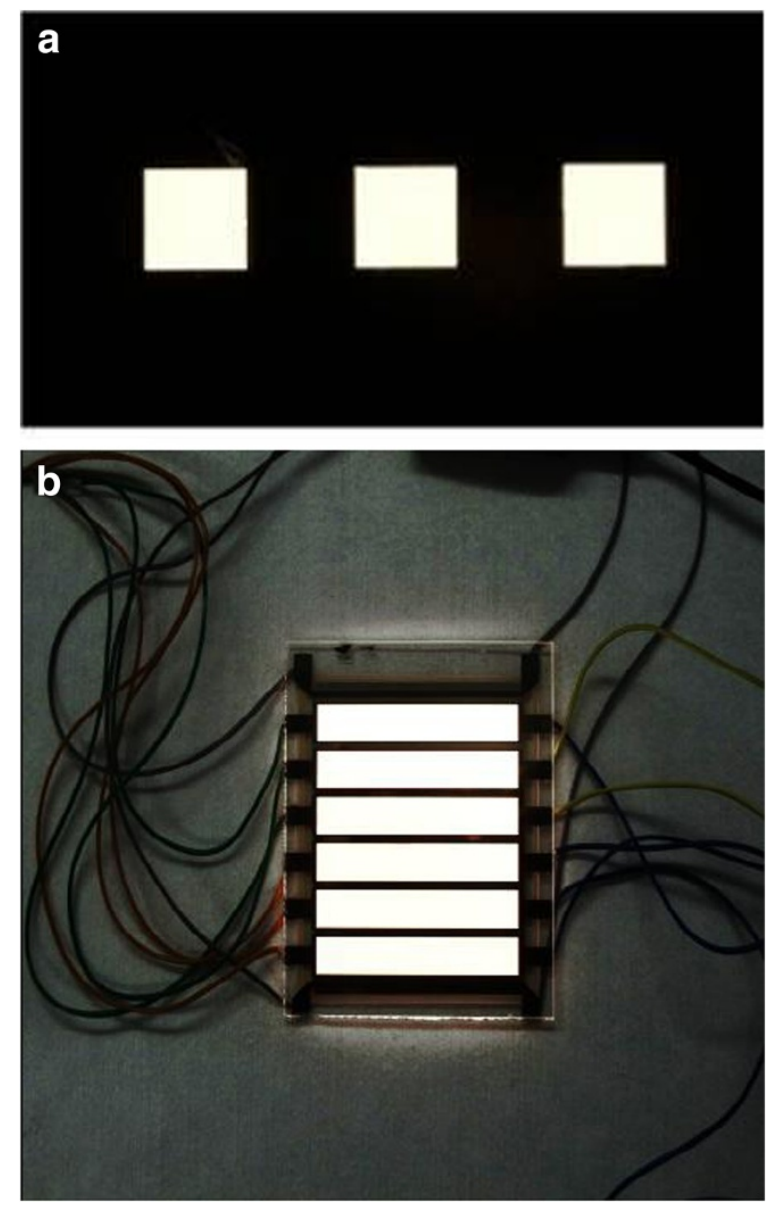

Figure 5 Photo images of (a) a $2 \mathrm{~mm}^{2}$ white OLED small-area test pixel and (b) $1911 \mathrm{~mm}^{2}$ large-area equivalent white OLED panel.

Using the Arrhenius equation, we plotted LT80 vs. reciprocal temperature $1 / T$ in a semi-log scale in Figure 6, and the fitted equation is

$$
\ln (L T(80))=-9.813+4920 * \frac{1}{\mathrm{~T}}
$$

Figure 6 shows the temperature dependent lifetime of OLED devices.

Additionally, an equivalent large-area white OLED lighting panel was also characterized. The panel was placed into a temperature controlled environment and voltage was measured at various ambient temperatures from $36.9^{\circ} \mathrm{C}$ to $56.6^{\circ} \mathrm{C}$. A low current density, $J_{\text {low }}=0.1 \mathrm{~mA} / \mathrm{cm}^{2}$, was applied to the panel so that minimal Joule heating is generated and $T \approx T_{j}$. The results are summarized in Table 1 and Figure 7 , from which we extracted the $K$ factor using Equation 1 . Note that, the $K$ factor is dependent on panel layout, because the voltage of the large-area OLED panel is related to how conductive the electrodes are [34]. For this particular panel layout when operating at $0.1 \mathrm{~mA} / \mathrm{cm}^{2}$, a $K=167^{\circ} \mathrm{C} / \mathrm{V}$ was extracted. The dotted line in Figure 7 shows an extrapolation to $20^{\circ} \mathrm{C}$. The $K$ factor will be used in the following steps to determine the junction temperature at the target luminance. 


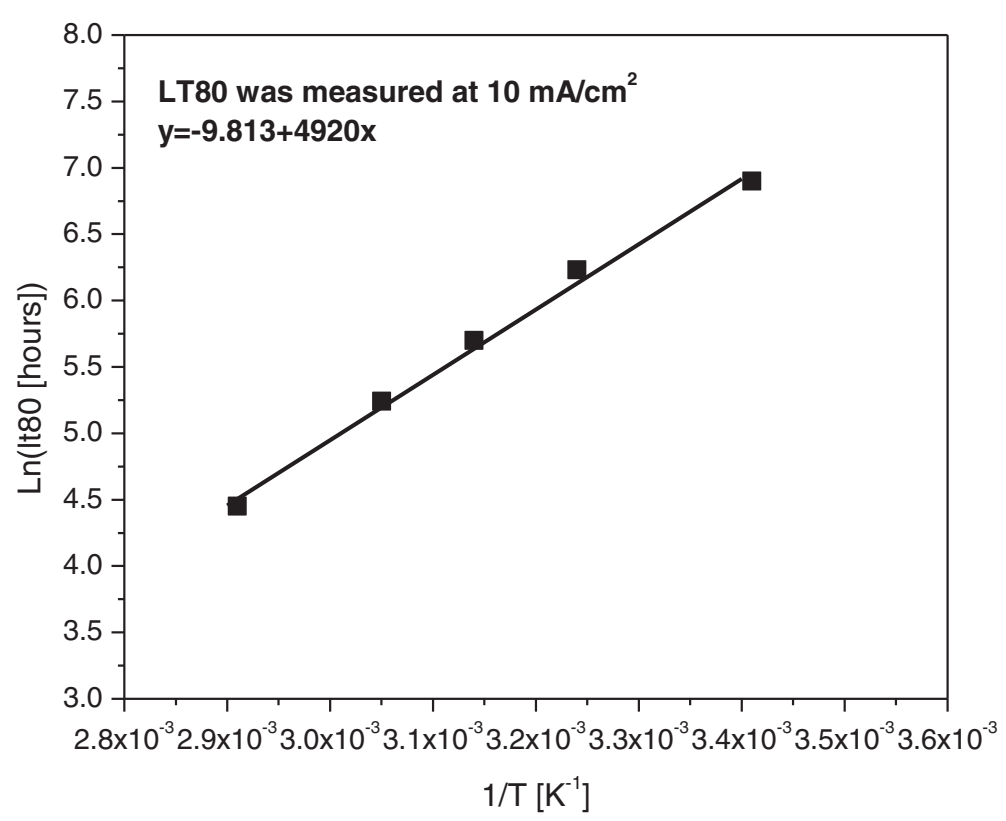

Figure 6 Plot of $\ln (\mathrm{LT} 80)$ vs. $1 / T$ of small-area white OLED test pixels in a semi-log scale at a target current density $J=10 \mathrm{~mA} / \mathrm{cm}^{2}$. The line is a fit to the measured data points.

The same OLED light panel was allowed to reach room temperature $\left(20^{\circ} \mathrm{C}\right)$, and $\Delta V$ was measured at a series of current densities (including the target current density), corresponding to different luminance levels. This was measured as follows: The panel was operated at $J_{\text {low }}=0.1 \mathrm{~mA} / \mathrm{cm}^{2}$ and initial voltage was measured $\left(V_{l}\right)$. The current density was then increased to $J_{\text {high }}=2 \mathrm{~mA} / \mathrm{cm}^{2}$ and the voltage $\left(V_{2}\right)$ was immediately measured. $V_{2}$ is the driving voltage at a measured current density before Joule heat is generated. Luminance was also measured at normal incidence to the OLED light panel. The panel was driven at this current density until a stable voltage $\left(V_{3}\right)$ was reached. $V_{3}$ is the voltage at the measured current density with Joule heating. Therefore, even though measured at the same current density, $V_{3}$ is lower than $V_{2}$ because the panel is now operated at an elevated temperature. Finally, a low current density $J_{\text {low }}=$ $0.1 \mathrm{~mA} / \mathrm{cm}^{2}$ was applied to the panel and the voltage $\left(V_{4}\right)$ was measured immediately. $V_{4}$ is the voltage when the panel is operated at an elevated temperature due to Joule heating. $\Delta V=V_{1}-V_{4}$ thus reflects the junction temperature. The above procedure is repeated for the following current densities: $J_{\text {high }}=2,5,10$ and $20 \mathrm{~mA} / \mathrm{cm}^{2}\left(10 \mathrm{~mA} / \mathrm{cm}^{2}\right.$ is the target current density). Figure 8 shows a schematic drawing of the $V_{1}, V_{2}, V_{3}$ and $V_{4}$ measurement.

Table 1 Voltage at a range of ambient temperatures measured at $J_{\text {low }}=0.1 \mathrm{~mA} / \mathrm{cm}^{2}$ for the white OLED light panel with an equivalent organic stack to the test pixels

\begin{tabular}{ll}
\hline Ambient temperature $\left[{ }^{\circ} \mathbf{C}\right]$ & Voltage $[\mathrm{V}] \mathbf{J}_{\text {low }}=\mathbf{0 . 1} \mathbf{~ m A} / \mathbf{c m}^{\mathbf{2}}$ \\
\hline 36.9 & 3.16 \\
46.2 & 3.11 \\
51.6 & 3.07 \\
56.6 & 3.04 \\
\hline
\end{tabular}




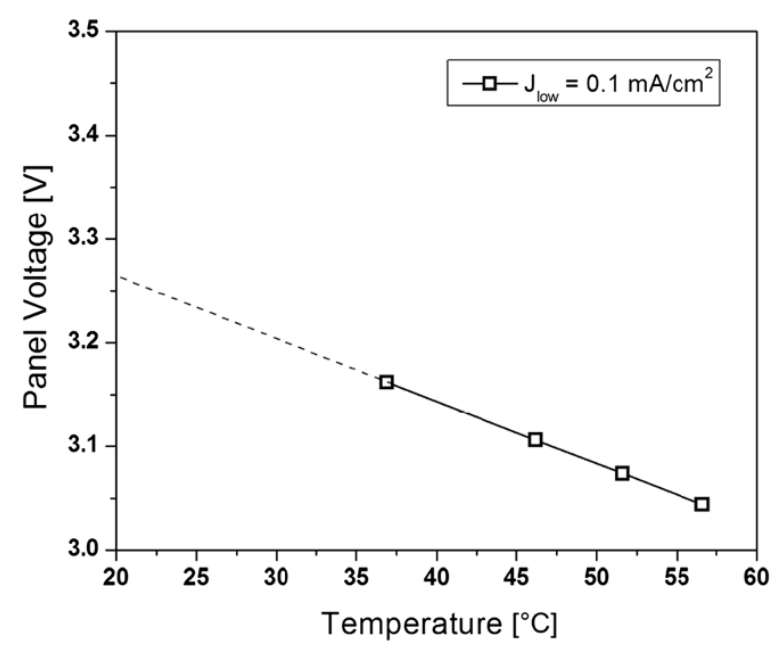

Figure 7 Voltage vs. temperature at $J_{\text {low }}=0.1 \mathrm{~mA} / \mathrm{cm}^{2}$ for a large area OLED light panel with an equivalent architecture to the OLED test pixel. The gradient gives $1 / K$, where $K=\left|\frac{\Delta T_{j}}{\Delta V}\right|$. For this panel operating at $0.1 \mathrm{~mA} / \mathrm{cm}^{2}, K=167^{\circ} \mathrm{CN}$. The dotted line shows an extrapolation to $20^{\circ} \mathrm{C}$.

Voltage, luminance, $\Delta V$ and calculated $T_{j}$ for different current densities are summarized in Table 2. Using Equation 3 and the $K$ factor extracted from Figure 7, $\Delta T_{j}$ was acquired. Next, using Equation $4, T_{j}$ at a certain current density can be determined. Also listed in Table 2 is $T_{j}$ extrapolated from Figure 7 using $V_{4}$. The slight difference comes from the heat transfer between ambient and the junction.

Figure 9 plots the panel voltage vs. calculated junction temperature at various current densities. The open square symbols were measured at a low current density $J_{\text {low }}=$ $0.1 \mathrm{~mA} / \mathrm{cm}^{2}$, and the dashed lines were calculated from the voltage differences. It is noteworthy that the junction temperatures of the white OLED lighting panels are extremely low in comparison to some other light sources (e.g. LED or incandescent bulbs). At $5 \mathrm{~mA} / \mathrm{cm}^{2}\left(2110 \mathrm{~cd} / \mathrm{m}^{2}\right)$ the junction temperature $T_{j} \approx 26^{\circ} \mathrm{C}$, while at target current density $10 \mathrm{~mA} / \mathrm{cm}^{2}\left(3800 \mathrm{~cd} / \mathrm{m}^{2}\right)$ the junction temperature $T_{j} \approx 33^{\circ} \mathrm{C}$. This is due in part to the incorporation of highly-efficient PHOLEDs, which enable low power, low operational temperature and long lifetime.

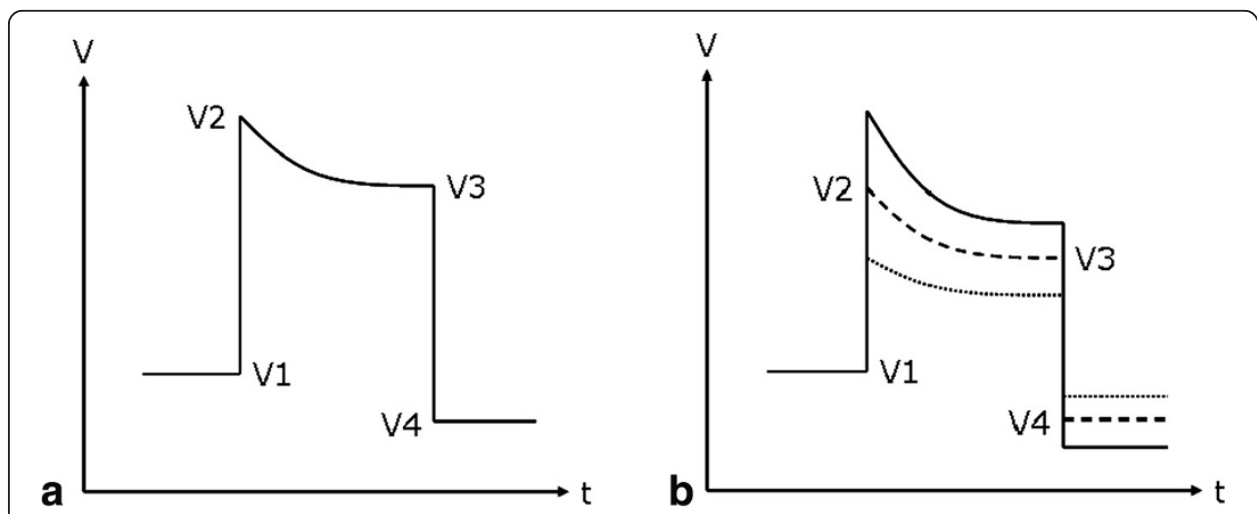

Figure 8 Schematic drawing of $V_{1}, v_{2}, v_{3}$ and $v_{4}$ measurement: (a) shows a single curve, (b) shows 3 curves, where the current density that is applied is varied from the lowest current density (dotted line), to an intermediate current density (dashed line) to the highest current density (solid line). 
Table 2 Luminance, and $\Delta V$ measured for the OLED light panel at $J_{\text {high }}=2,5,10$ and $20 \mathrm{~mA} / \mathrm{cm}^{2}$, where, $\Delta V=V_{1}-V_{4}$ calculated $\Delta T_{j}$ and $T_{j}$ based on the $K$ factor. Also listed is extrapolated $T_{j}$ from Figure 7 using $V_{4}$

\begin{tabular}{llllll}
\hline $\begin{array}{l}\text { Current density } \\
{\left[\mathbf{m A} / \mathbf{c m}^{2}\right]}\end{array}$ & $\begin{array}{l}\text { Luminance } \\
{\left[\mathbf{c d} / \mathbf{m}^{2}\right]}\end{array}$ & $\begin{array}{l}\boldsymbol{\Delta} \mathbf{V}=\mathbf{V} \mathbf{1}-\mathbf{V} \mathbf{4} \\
{[\mathbf{V}]}\end{array}$ & $\begin{array}{l}\boldsymbol{\Delta} \mathbf{T}_{\mathbf{j}} \\
{\left[{ }^{\circ} \mathbf{C}\right]}\end{array}$ & $\begin{array}{l}\mathbf{T}_{\mathbf{j}} \\
{\left[{ }^{\circ} \mathbf{C}\right]}\end{array}$ & $\begin{array}{l}\text { Extrapolated } \mathbf{T}_{\mathbf{j}} \\
{\left[{ }^{\circ} \mathbf{C}\right]}\end{array}$ \\
\hline 2 & 870 & 0.01 & 2.2 & 22.2 & 23.8 \\
5 & 2,110 & 0.03 & 5.2 & 25.2 & 26.8 \\
10 & 3,800 & 0.08 & 12.7 & 32.7 & 34.2 \\
20 & 7,660 & 0.16 & 26.5 & 46.5 & 48.0 \\
\hline
\end{tabular}

The final step in this process is to use the junction temperature to predict the lifetime of the OLED light panel. As shown in Figure 9, at $10 \mathrm{~mA} / \mathrm{cm}^{2}$, the junction temperature calculated for the panel is $T_{j} \approx 34^{\circ} \mathrm{C} \approx 307 \mathrm{~K}$. If we substitute this temperature into the equation for the line of best fit from Figure 6, we extrapolated LT80 $=526$ hrs. This is the lifetime which we have predicted for the large area OLED light panel at room temperature at $10 \mathrm{~mA} / \mathrm{cm}^{2}$. Similarly, lifetime at other luminance levels (i.e. current densities) can also be calculated from this method.

To further validate this prediction, we life-tested an OLED panel at room temperature $\left(20^{\circ} \mathrm{C}\right)$ at $J=10 \mathrm{~mA} / \mathrm{cm}^{2}$ so as to compare the measured LT80 with the above prediction. The life-test curve of the OLED panel driven at $J=10 \mathrm{~mA} / \mathrm{cm}^{2}$ is shown in Figure 10. Also included for comparison is the life-test curve for the equivalent pixel at the same current density. For the pixel, the initial luminance $L_{o}=3,780 \mathrm{~cd} / \mathrm{m}^{2}$, while for the panel $L_{o}=$ $3,800 \mathrm{~cd} / \mathrm{m}^{2}$. Normalized luminance for the large-area panel was calibrated for total light emission by measurement before and after life test inside a 20" integrating sphere.

Figure 10 shows that the measured lifetime of the large-area OLED light panel at $10 \mathrm{~mA} / \mathrm{cm}^{2}$ is LT80 $=512 \mathrm{hrs}$. This value agrees very well with our indirect prediction of $\mathrm{LT} 80=526 \mathrm{hrs}$. The small difference can be readily attributed to substrate-tosubstrate variations and small errors in any temperature or voltage measurements. The validity of the proposed method has therefore been demonstrated. In comparison,

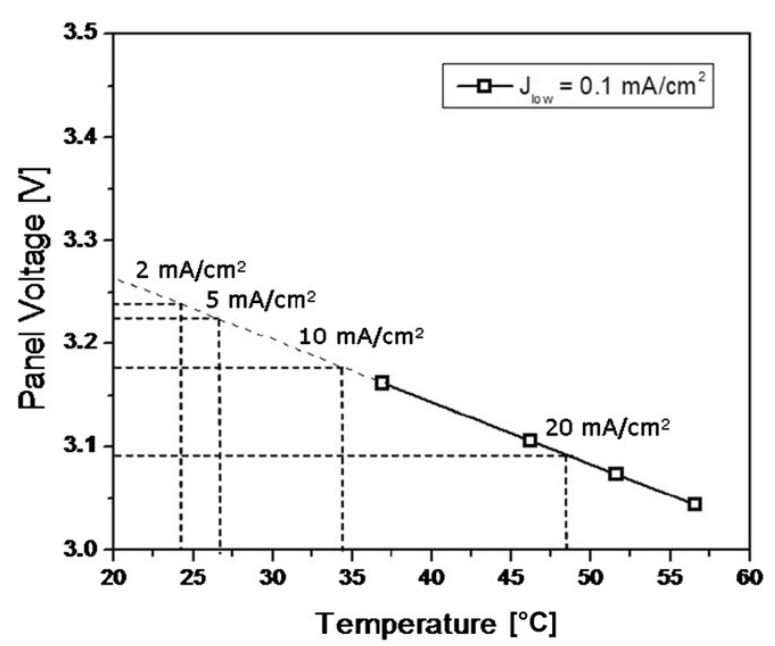

Figure 9 Panel voltage vs. temperature plot showing calculated junction temperatures at different applied current densities. $J_{\text {low }}=0.1 \mathrm{~mA} / \mathrm{cm}^{2}$, and $J_{\text {high }}=2,5,10$ or $20 \mathrm{~mA} / \mathrm{cm}^{2}$. 


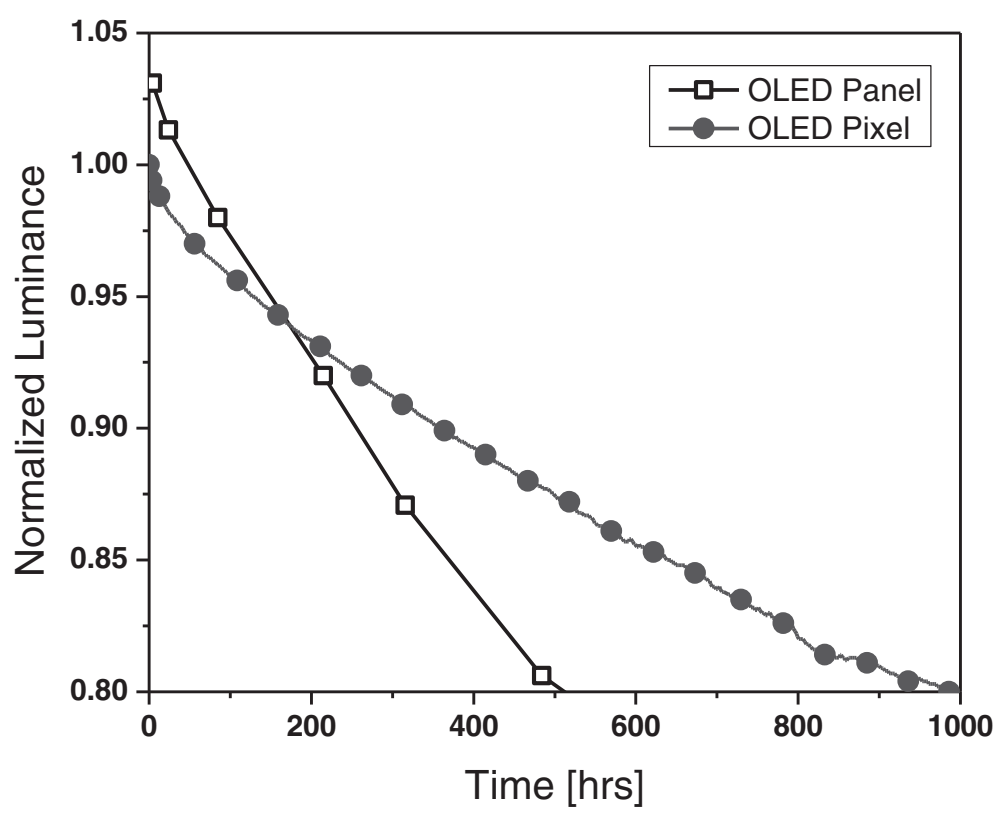

Figure 10 Lifetime plots for an equivalent OLED test pixel (circles) and large-area light panel (squares). Both lifetime measurements were taken at room temperature $\left(20^{\circ} \mathrm{C}\right)$ at $J=10 \mathrm{~mA} / \mathrm{cm}^{2}$. For the pixel, $L_{o}=3,780 \mathrm{~cd} / \mathrm{m}^{2}$, while for the panel $L_{o}=3,800 \mathrm{~cd} / \mathrm{m}^{2}$. Normalized luminance for the large area panel was calibrated for total light emission by measurement before and after life test inside a 20 " integrating sphere.

LT80 $=988 \mathrm{hrs}$ is acquired for an equivalent pixel. This data also matches the result extrapolated from ALT with LT80 $=997$ hrs (from Figure 3). The comparison of lifetime of the OLED panel acquired from direct measurement and indirect prediction, and the lifetime of the equivalent testing pixel is summarized in Table 3. The difference between the panel lifetime and pixel lifetime is a result of their different operating temperatures at the same driving current density: the pixel was operating at approximately $20^{\circ} \mathrm{C}$ while the panel was measured to have a junction temperature of $33^{\circ} \mathrm{C}$.

As can be seen from Table 3, a $13^{\circ} \mathrm{C}$ temperature difference results in $1.9 \mathrm{x}$ lifetime reduction. Improved thermal management of large-area OLED panels can enhance lifetime. Various approaches have been evaluated and developed. For example, metal shunting grids may be placed on the anode to improve heat distribution [28,35]; an additional metal plate may be attached to the substrate as a heat sink or a thicker cathode may be used [36]; and replacing the conventional cover glass with thin film encapsulation also enhances heat dissipation [37,38]. In general, employing highly efficient PHOLEDs to reduce non-emissive exciton decay and optimizing the layout design to minimize Joule heating are the two key factors that enable low temperature operation of large-area OLED lighting panels, and long lifetime.

Table 3 Summary of LT80 of a white OLED lighting panel and an equivalent small-area test pixel at $10 \mathrm{~mA} / \mathrm{cm}^{2}$ by prediction and by direct measurement

\begin{tabular}{lll} 
& LT80 [hrs] at $\mathbf{1 0 ~} \mathbf{~ A A} / \mathbf{c m}^{2}$ & \\
\cline { 2 - 3 } & Pixel $\mathbf{2} \mathbf{~ m m}^{\mathbf{2}}$ & Panel $\mathbf{1 9 . 1 1 \mathbf { ~ c m } ^ { 2 }}$ \\
\hline Direct measurement & 988 & 512 \\
Indirect prediction & 997 (ALT result) & 526 \\
\hline
\end{tabular}




\section{Conclusions}

In this work, we proposed a new method to address the challenge in life testing largearea OLED lighting panels. Based on the thermal dependence of OLED lifetime and by measuring the junction temperature of a panel under test at a target luminance, we could determine the panel lifetime according to that temperature. The method was validated on a $1911 \mathrm{~mm}^{2}$ large-area white OLED panel and the calculated LT80 526 hours, agreed well with the life test result LT80 $=512$ hours. The advantage of this indirect method is to avoid driving panels at an accelerated condition which induces degradation, as well as to save time life testing. We believe this novel method offers a reliable and practical way of predicting lifetime for large-area OLED panels.

Competing interests

The authors declare no competing financial interests.

\section{Authors' contributions}

HP carried out the experiments and presented the first draft of the paper. LM, MW conceived original ideas and participated in the design of the study. RM, JB participated in the technical discussion and helped to draft the manuscript. All authors read and approved the manuscript.

\section{Acknowledgement}

The authors would like to thank Dr. Peter A. Levermore for his contribution in this work. This work is partially supported by U.S. Department of Energy under contract DE-SC0004281.

Received: 6 March 2014 Accepted: 31 March 2014

Published: 23 May 2014

References

1. Tang C, Van Slyke S: Organic electroluminescent diodes. Appl Phys Lett 1987, 51:913.

2. Solid State Lighting OLED basics. http://www1.eere.energy.gov/buildings/ssl/sslbasics_oledbasics.html

3. Solid State Lighting OLED manufacturing roundtable summary. http://apps1.eere.energy.gov/buildings/ publications/pdfs/ssl/ssl-oled-roundtable-summary_2013.pdf

4. Levermore P, Dyatkin A, Elshenawy Z, Pang H, Silvernail J, Krall E, Kwong R, Weaver M, Ma R, Brown J, Qi X, Forrest S: Phosphorescent OLEDs for high efficacy long lifetime solid state lighting. J Photonics Energy 2012, 2:021205.

5. Komoda T, Yamae K, Kittichungchit V, Tsuji H, Ide N: Extremely high performance white OLEDs for lighting. SID Symp Digest Tech Papers 2012, 43(1):610.613. doi/10.1002/sdtp.2012.43.issue-1/issetoc.

6. Xu X, Weaver M, Brown J: Phosphorescent Stacked OLEDs for Warm White Lighting Applications. SID 13 Tech Digest 2013, 44:p845-p847.

7. Pang H, Mandlik P, Levermore P, Silvernail J, Ma R, Brown J: Large-area high-efficiency flexible PHOLED lighting panels. Proc of SPIE 2012, 8476(4):p 84761C.

8. Sasabe H, Kido J: Development of high performance OLEDs for general lighting. J Mater Chem C 2013, 1(9):1699-1707.

9. Chang Y-L, Lu Z-H: White Organic Light-Emitting Diodes for Solid-State Lighting. J of Display Tech 2013, 9(6):459-468.

10. Philips Lumiblade. http://www.lighting.philips.com/main/lightcommunity/trends/oled/lumibladeoledgl350.wpd

11. Acuity Brands OLED luminaire. www.AcuityBrands.com/OLED

12. LG Chem OLED lighting. http://www.oled-info.com/lg-chem-upgrades-their-flexible-oled-and-delays-productionq4-2013

13. Panasonic OLED lightings. http://panasonic.co.jp/corp/news/official.data/data.dir/2012/07/en120719-4/en120719-4.html

14. Lumieotec OLED panels. http://www.lumiotec.eu/index-en.html

15. Osram OLED lighting. http://www.osram.com/osram_com/news-and-knowledge/oled-home/index.jsp

16. Konica Minolta OLED lighting. http://www.konicaminolta.com/oled/index.html

17. Verbatim Velve OLED panel. http://www.verbatimlighting.com/article/oled/

18. DOE Energy Efficiency and Renewable Energy: LED Basics. http://www1.eere.energy.gov/buildings/ssl/ sslbasics_ledbasics.html

19. Tim W: Fact or fiction - LEDs don't produce heat. http://ledsmagazine.com/features/2/5/8

20. CREE: Thermal management of CREE $^{\oplus}$ XLamp $^{\oplus}$ LEDs. www.cree.com/xlamp

21. Baldo MA, O'Brien DF, You Y, Shoustikov A, Sibley S, Thompson ME, Forrest SR: Highly efficient phosphorescent emission from organic electroluminescent devices. Nature 1998, 395:151-154.

22. Weaver MS, Tung Y-J, D'Andrade B, Esler J, Brown JJ, Lin C, Mackenzie PB, Walters RW, Tsai J-Y, Brown CS, Forrest SR, Thompson ME: Advances in blue phosphorescent organic light-emitting devices. SID'06 Tech Digest 2006, 37:p127.

23. Park Jl, Bae SJ: Direct prediction methods on lifetime distribution of organic light-emitting diodes from accelerated degradation tests. IEEE Tran Reliability 2010, 59(1):74-90.

24. McMahon TJ: Accelerated testing and failure of thin-film PV modules. Prog Photovolt Res Appl 2004, 12:235-248.

25. Trevisanello L, Meneghini M, Mura G, Vanzi M, Pavesi M, Meneghesso G, Zanoni E: Accelerated life test of high brightness light emitting diodes. IEEE Tran Device Mater Reliab 2008, 8(2):304-311. 
26. Park J, Kawakami Y: Temperature-dependent dynamic behaviors of Organic Light-Emitting Diode. J Disp Technol 2006, 2(4):333-340.

27. Slawinski M, Bertram D, Heuken M, Kalisch H, Vescan A: Electrothermal characterization of large-area organic light-emitting diodes employing finite-element simulation. Org Electron 2011, 12:1399-1405.

28. Poppe A, Pohl L, Kollar E, Kohari Z, Lifka H, Tanase C: Methodology for thermal and electrical characterization of large area OLEDs. 25th IEEE Semi-Therm Symp; 2009.

29. Merkel CW, Helander MG, Qiu J, Lu ZH: In situ lifetime testing of organic light emitting diodes. Proc of SPIE 2012, 8476:847622-847631.

30. Juan C-J, Tsai M-J: Implementation of a novel system for measuring the lifetime of OLED panels. IEEE Trans Consum Electron 2003, 49(1):1-5.

31. Siegal B: Measurement of junction temperature confirms package thermal design. Laser Focus World 2003, 39(11):pS12.

32. Lock DA, Hall S, Prins AD, Crutchley BG, Kynaston S, Sweeney SJ: LED junction temperature measurement using generated photocurrent. J Disp Technol 2013, 9:5.

33. Tsai Y-S, Wang S-H, Chen C-H, Cheng C-L, Liao T-C: Using copper substrate to enhance the thermal conductivity of top-emission organic light-emitting diodes for improving the luminance efficiency and lifetime. Appl Phys Lett 2009, 95:233306.

34. Ma R, Levermore PA, Pang H, Mandlik P, Hack M, Brown JJ: Challenges and Opportunities in Scaling Up OLEDs for Lighting Applications. Proc SID Int Symp Dig Tech Papers 2011, 66.4:983.

35. Park J, Lee J, Noh Y-Y: Optical and thermal properties of large-area OLED lightings with metallic grids. Org Electron 2012, 13:184-194.

36. Cok RS, Coleman J, Leon F, Mazzarella J: Heat distribution in AMOLEDs. J SID 2005, 13/10:849-855

37. Bergemann K, Krasny R, Forrest SR: Thermal properties of organic light-emitting diodes. Org Electron 2012, 13:1565-1568.

38. Park J, Ham H, Park C: Heat transfer property of thin-film encapsulation for OLEDs. Org Electron 2011, 12:227-233.

doi:10.1186/2196-1107-1-7

Cite this article as: Pang et al:: Thermal behavior and indirect life test of large-area OLED lighting panels. Journal of Solid State Lighting 2014 1:7.

\section{Submit your manuscript to a SpringerOpen ${ }^{\circ}$ journal and benefit from:}

- Convenient online submission

Rigorous peer review

- Immediate publication on acceptance

- Open access: articles freely available online

- High visibility within the field

Retaining the copyright to your article

Submit your next manuscript at $\boldsymbol{~ s p r i n g e r o p e n . c o m ~}$ 